\title{
Mechanical Analysis of Steel Box Girder During Incremental Launching
}

\author{
Wu Hongsheng \\ The 5th Construction Company LTD. \\ China 15th Corporation \\ Luoyang, China \\ e-mail: 350923812@qq.com \\ $\mathrm{Zou} \mathrm{Yu}$ \\ School of Civil Engineering \\ Shenyang University of Technology \\ Shenyang, China \\ e-mail: zy574839@163.com
}

\begin{abstract}
In order to clear the stress of steel box girder born complex stress in the process of incremental launching, launching procedure is simulate by ABAQUS, mechanical performance and local buckling are analyzed, incremental launching cases are studied. Case studied results show that the design of this bridge meets the demand in the mass. The post buckling analysis shows that even under the unfavorable condition, just make sure the bearing surface is full contact with the girder bottom, the plastic deformation occur slightly and will not affect the safety of the structure.
\end{abstract}

Keywords- incremental launching method; post-buckling; FEM software; ABAQUS; finite elements method

\section{INTRODUCTION}

The first HouDingxiang Bridge is a continuous steel box girder bridge with three spans; the bridge length is $137 \mathrm{~m}(38 \mathrm{~m}+61 \mathrm{~m}+38 \mathrm{~m})$. The cross section of this bridge is simple-box with triple-cell girder, the height of the box girder is $3.1125 \mathrm{~m}$, and the length of the bottom of box girder is $11.25 \mathrm{~m}$, the inner web plate is $3 \mathrm{~m}$ high.

At present, most bridge design institute to use finite beam elements method to analyze the mechanical properties at the finished state and the construction states, a shortcoming will appear by using the beam elements method to calculate the structure stress, but the simplified method can not determine the accurate stress state on the bridge, especially use it to calculate the structure which has thin wall steel box[1]-[2]. During the incremental launching, the concentrated force act on the bottom of the box, which may cause irreversible deformation [3]-[6]. So it is necessary to use FEM software like ABAQUS to modeling full bridge. During launching the bridge, the reaction force on the support bear reaches a certain level and will destroy the web and the diaphragms. These damages will cause an irreversible reduction of bearing capacity about the bridge. As a result, it is essential to use

\author{
Ma Junming \\ The 5th Construction Company LTD. \\ China 15th Corporation \\ Luoyang, China \\ e-mail: liym@126.com \\ Wang Haijun* \\ School of Civil Engineering \\ Shenyang University of Technology \\ Shenyang, China \\ *Corresponding Author: Wang_navy@ hotmail.com
}

full FEM model and partial model to analyze the stress state during the bridge construction.

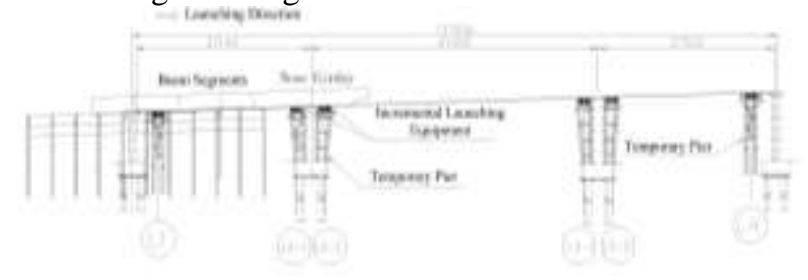

Figure 1. Bridge launching



Figure 2. Launching equipment on the temporary pier

\section{MECHANICAL PROPERTIES ANALYSIS DURING INCREMENTAL LAUNCHING}

\section{A. Model building}

HouDingxiang first bridge is divided into 16 beam segments according to the design, modeling the segment individually when we use FEM software before analyzing; add the different beam segments due to the construction steps. For the numerical model, the bottom of the steel box is supposed to be horizontal without pre-camber[7]-[11]. The beams keep straight and level during the launching. At the front of the beams, there is a steel nose girder, the nose girder with the length of $25 \mathrm{~m}$, and a bevel at the front bottom of the nose girder, the bevel can help the nose girder slide on the support bear smoothly when reaching 
the front pier. The support bear contact with the bottom of the steel box girder when launching the bridge. In this model, we simplify the launching equipment as a cuboids, whose length of the top surface is $2.15 \mathrm{~m}$ and width is $0.5 \mathrm{~m}$. The launching process includes five construction conditions, for each condition, the gravity load at first step is applied and forward is launched at the second step. In order to get closer to the actual situation, coupling the end of beam and the front of the nose girder with two reference points, this constraint allows the neutral axis adjust to account for the bending moment. Rigid body constraint is used for the cuboids. In order to simulate the launching process, the beam segments and nose girder stay still and apply a displacement load on the cuboids, so the cuboids moves backward as the incremental equipment, the contacting property between the support bear and steel box bottom is 'hard contact' at the normal direction and frictionless at the tangent direction, constrain the translation of X Z degree of freedom and the rotation of $\mathrm{Z}$ $Y$ degree of freedom at the reference point which coupling with the end of the beam, also constrain the translation of $\mathrm{X}$ degree of freedom and the rotation of $\mathrm{Z} \mathrm{Y}$ degree of freedom.

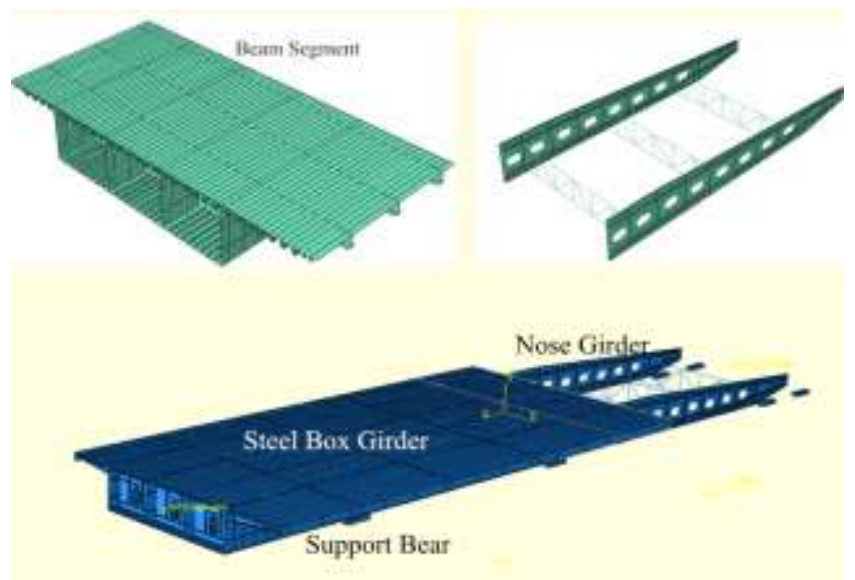

Figure 3. Incremental Launching model

\section{B. Launching analysis}

Launching condition one: During this launching stage, the bridge has five beam segments, the total length is $66 \mathrm{~m}$ (includes nose), and will move forward $31 \mathrm{~m}$. When move $14.3 \mathrm{~m}$, the box girder endure the maximum support reaction force at support bear $\mathrm{L} 1$, at the same time and same place, the maximum mises stress occurred, the maximum mises stress reach $151 \mathrm{MPa}$ and the maximum reaction force at the support bear L1 reach 3960KN (in this paper, the reaction force means the sum of the force at both side of the support bears), the maximum vertical displacement at the front nose girder is $25 \mathrm{~mm}$. During the whole stage, the stress on the steel box girder is in the safe range.

Launching condition two: On the basis of condition one, this launching stage adds three more beam segments, the total length is $68 \mathrm{~m}$ and they will move $18 \mathrm{~m}$. During launching, the maximum stress is $223.8 \mathrm{Mpa}$ and the maximum reaction force reach $4570 \mathrm{KN}$, both occur at the end of launching. The cantilever length keeps increasing and the maximum vertical displacement at the front nose girder is $89 \mathrm{~mm}$. The stress in the box girder does not exceed the allowed range all the time.

Launching condition three: At this launching stage, the number of beam segments reach 10 and the total length of the bridge is $86 \mathrm{~m}$, the launching distance is $27 \mathrm{~m}$, when the launch distance reaches $11.5 \mathrm{~m}$, the maximum of reaction force occur at the L2-2 support bear, reach $6520 \mathrm{KN}$, at the same time, the maximum vertical displacement at the front nose as large as $230 \mathrm{~mm}$, this is the most unfavorable condition. When the launch distance reaches $19.9 \mathrm{~m}$, the stress on the steel box girder reaches $368 \mathrm{MPa}$ and exceeds the allowable stress. At this moment, the contractor must pay special attention to this situation, the analysis model shows that the reaction force on the L2-1 support bear is very low, this is not match the value calculated by design institution, the reason is that, the designer use beam element method to simulate the launching process, this cause the boundary condition do not match the actual situation; In fact, the beam will sagging during launching and this deformation cause the L2-1 support bear non-contact with the bottom of the box girder, but in the original design, the L2-1 support bear will always contact with the bottom of the box and bear the gravity of the structure. In order to solve this problem, the contractor should take measures like increasing the height of L2-1, let the L2-1 shear the reaction force which act on the L2-2 support bear, then the support reaction force match the original design.

Launching condition four: At this stage, the number of launching beam segments reach 13, the total length of the bridge is $111 \mathrm{~m}$ and the launching distance is $21 \mathrm{~m}$. After launching condition three, the nose girder already reach L3-1 support bear and the most unfavorable condition has passed, so the maximum Von-mises stress is reduced to $274 \mathrm{MPa}$ when launching $8.4 \mathrm{~m}$, the maximum reaction force is $4825 \mathrm{KN}$ occurred at L2-2 support bear, the maximum stress do not exceed the allowable stress, the structure keeps security.

Launching condition five: This is the last construction condition, at this stage, there are 16 beam segments and the total length is $137 \mathrm{~m}$. At the end of launching, the bridge will reach the final place. The launching distance is $23.02 \mathrm{~m}$. During launching, the maximum mises stress on the box girder is $228 \mathrm{MPa}$, occurred when launching distance reaches $13.24 \mathrm{~m}$, at the same moment, the maximum reaction force on the L3-1 support bear is $4990 \mathrm{KN}$. The maximum vertical displacement at the front nose girder is $110 \mathrm{~mm}$; this deformation is still in elastic state, which means this deformation is recoverable. During the entire launching stage, the structure will not be damaged.

As the data shows in table I, the condition three is the most unfavorable condition, both the stress and reaction force achieve the maximum, this occurs when the nose girder on the eve of reach the L3-1 support bear, at this moment, the steel box girder has the maximum cantilever 
length, what is worse, the box girders lies across the maximum span will sag, and this deformation cause the L2-1 support bear non-contact with the box bottom, the L2-2 will undertake most of the structure gravity, the concentrate force act there will damage the box girder. The contractor must pay attention to this situation and adjust the height of the adjacent bear to reduce the maximum force.

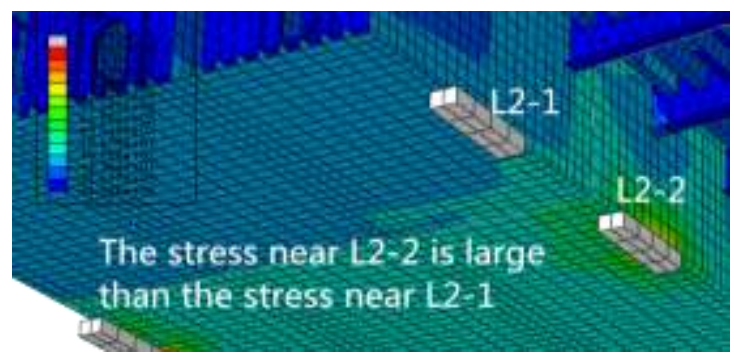

Figure 4. The stress near the support bears



Figure 5. Deformation cause the bear uncontact with girder

TABLE I. THE MAXIMUM REACTION FORCE AND MISES STRESS

\begin{tabular}{|c|c|c|}
\hline $\begin{array}{c}\text { Construction } \\
\text { Condition }\end{array}$ & $\begin{array}{c}\text { Maximum } \\
\text { Reaction Force }\end{array}$ & Maximum Stress \\
\hline One & $3960 \mathrm{KN}$ & $151 \mathrm{MPa}$ \\
\hline Two & $4570 \mathrm{KN}$ & $223 \mathrm{MPa}$ \\
\hline Three & $6520 \mathrm{KN}$ & $368 \mathrm{MPa}$ \\
\hline Four & $4826 \mathrm{KN}$ & $274 \mathrm{MPa}$ \\
\hline Five & $4990 \mathrm{KN}$ & $228 \mathrm{Mpa}$ \\
\hline
\end{tabular}

\section{Buckling analysis}

The front analysis has determine the stress distribution and the reaction force in the launching process, but the destruction of such thin-wall steel box girder is different from the destruction on the entity structure, this is due to the buckling characteristic, unlikely the structure that directly respect to the material destruction, the steel box girder will buckle first and then cause the material destruction, most design institution use the software basis on the beam element method to calculate the stress situation, these software is unable to analyze the buckling circumstance. Therefore, the result is not suitable to the actual situation. So the buckling analysis of thin-walled structures is particularly important.

This paper does not analyze the stress concentration caused by beam sagging, the impact comes from the sagging can be reduced by adjust the height of adjacent support bear, here will analyze the buckling circumstance when the support bear surface is fully contact with bottom of the steel box girder, we choose the beam segment with minimum web thickness to determine the potential buckling, set the support bear in the middle place of two diaphragms during loading, for the purpose to simulate the most adverse condition.

First analyze the eigenvalue of the model, we only concern about the buckling at the place where contact with the support bear, and this is also the only place the buckle will occur, so use the partial model to analyze the potential web buckling, in order to determine the potential buckling situation on the steel box girder when acting on concentrated force during launching. After get the eigenvalue from buckling analysis, put the result and the imperfection scale factor into the post buckling analysis. For this model, we use 0.025 as the imperfection scale factor. For the FEM software, if there is no mesh imperfection, the software will regard the structure as the ideal structure, during the loading process, the structure will not buckling, the material destruction will occurred only, the load $(6520 \mathrm{KN})$ was used for post buckling analyze, this load comes from when the most unfavorable condition happened during launching condition three, that time the cantilever beam segments have the maximum cantilever length and the nose girder will contact with L31 support bear soon. Then the L2-2 support bear undertaking the maximum gravity of the launching beams. For the eigenvalue analysis, apply the load with100N on the support bear, use subspace method to get the eigenvalues, the eigenvalues showing in table II, the fist order eigenvalue is $2.54668 \mathrm{E}+05$. In order to obtain the eigenvalue, the material must be acted elastically, so the result can not reflect the real situation. Therefore, the structure just for modal analysis, the buckling situation of the structure can not be understood enough. So we will use post buckling method to analyze the bearing capacity of the web during the process of launching.

The box girder use steel Q345, during the post buckling analysis, introducing the plasticity property and the mesh imperfection. According to the material constitutive equation, the stress is $276 \mathrm{MPa}$ when the material enters plastic state. After applying the load of $6520 \mathrm{KN}$ on the bear, the stress distribution showing as Figure 6, the maximum mises stress is $345 \mathrm{MPa}$, which is not exceed the allowable stress. It was reduced $6 \%$ by $368 \mathrm{MPa}$. The bottom of the box with stress $345 \mathrm{MPa}$ has already enter the plastic state, the maximum deformation is $5.8 \mathrm{~mm}$ and the equivalent plastic strain is only $0.55 \mathrm{~mm}$, which means the box girder will occur slightly plastic deformation, so even acting on the maximum reaction 
force, the deformation occurred on the web will not endanger the structure.

TABLE II. THE EIGENVALUE

\begin{tabular}{|c|c|}
\hline Modal & Eigenvalue \\
\hline 1 & $2.54668 \mathrm{E}+05$ \\
\hline 2 & $2.54805 \mathrm{E}+05$ \\
\hline 3 & $2.96756 \mathrm{E}+05$ \\
\hline 4 & $2.96981 \mathrm{E}+05$ \\
\hline 5 & $3.32002 \mathrm{E}+05$ \\
\hline 6 & $3.32367 \mathrm{E}+05$ \\
\hline 7 & $4.01045 \mathrm{E}+05$ \\
\hline 8 & $4.01352 \mathrm{E}+05$ \\
\hline 9 & $4.43899 \mathrm{E}+05$ \\
\hline 10 & $4.44076 \mathrm{E}+05$ \\
\hline
\end{tabular}

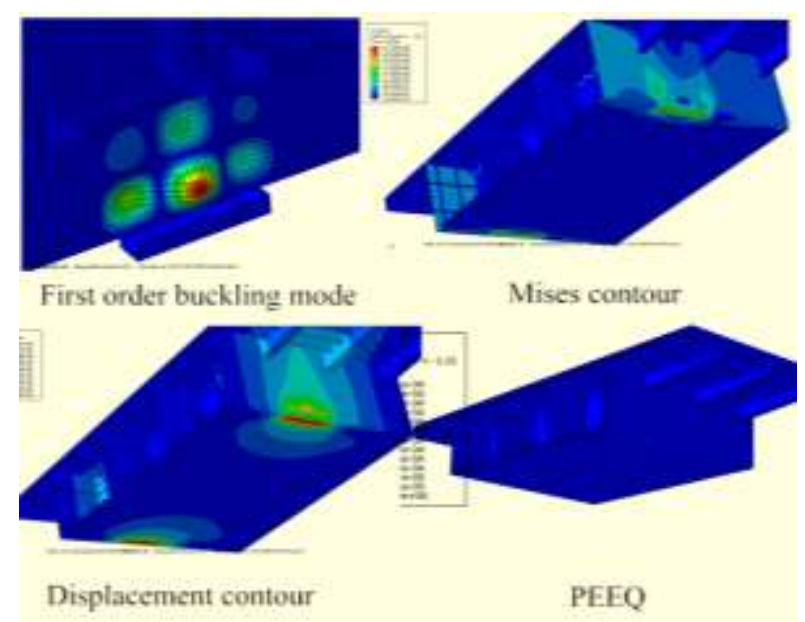

Figure 6. Buckling analysis

\section{AVOID UNDESIRABLE CONDITION}

During the actual construction, it is difficult to achieve the idea state in the numerical simulation, like the uneven settlement will worsen the support boundary condition. The height difference between the both side support bear will make one bear non-contact with the box girder, the reaction force on the other side will exceed the bearing capacity and cause damage. The deviation along the axial direction will cause the reaction force not acting on the web but on the bottom of box girder or diaphragms, this may cause the structure in an extremely unfavorable condition. During the construction process, the contractor should guarantee the accuracy of construction.

\section{CONCLUSION}

(1) The launching analysis shows that the steel box girder meet the requirements generally in the process of launching. The structure will in the most unfavorable condition in the launching condition three, the maximum reaction force and the maximum Vonmises stress appear in the beams. The contractor should pay attention to the stress changing at this moment, by adjusting the height of L2-1 support bear to shear the reaction force act on the L2-2.

(2) In the launching process, the steel box girder will sagging and cause support boundary condition changing, it also increase the reaction force on the bear, worsen the stress condition in the structure, therefor the reaction force should be under closely monitoring and control, by adjusting the launching equipment to ensure the reaction force act on the structure in a safe range.

(3) The post buckling analysis shows that even under the unfavorable condition, just make sure the bear surface is full contact with the girder bottom, the plastic deformation occur slightly and will not affect the safety of the structure.

\section{REFERENCES}

[1] Rosignoli M. Bridge Launching. Thomas Telford Ltd, 2002.

[2] Rosignoli M, "The evolution of a technique incremental bridge launching," Civil. Eng, 1997, pp. 27-36.

[3] Rosignoli M, "Thrust and guide device for launched bridges," Bridge Eng., 2008, pp. 75-83

[4] Tang M. Manzanarez R., Nader M, Abbas S., Ba ker G., "Replacing the East Bay Bridge", Civil Engineering, ASCE, Vol. 70, No. 10, 2000, pp. 38-43.

[5] McDaniel C. C., Uang C. M., Seible F., "Cyclic Testing of Builtup Ste e 1 Shear Links for the New Bay Bridge", Journal of Structural Engineering, Vol. 129, No. 6, 2003, pp. 801-809.

[6] Arici M., Granata, M. F. "Analysis of curved incrementally launched box concrete bridges using the transfer matrix method", Bridge Struct. , 3(3-4), 2007, pp. 165-181.

[7] Tianyong Jiang, Zhongchu Tian, Jinghua Xu. "Key technologies of whole incremental launching construction control for inclined continuous box girder with steep longitudinal gradient", Applied Mechanics and Materials, vol. 204-208, 2012, pp. 2034-2039.

[8] Xu Kaiming. "Incremental launching construction method for steel truss suspension bridge", Advanced Materials Research, vol. 204210, 2011, pp. 842-845

[9] Yezhi Zhang, Rudeng Luo. "Patch loading and improved measures of incremental launching of steel box girder", Journal of Constructional Steel Research, vol. 68, 2012, pp, 11-19.

[10] Jinfeng Wang, Jianping Lin, Chunlei Chen, Zhicheng Zhang. "Simulation analysis and control research of long multi-span composite bridge with incremental launching construction", Proceedings of the 11th International Conference of Chinese Transportation Professionals, 2011, pp. 3078-3090.

[11] Jie Dai, Jin Di, Fengjiang Qin, Min Zhao, Wenru Lu. "Finite element analysis on incremental launching constructionfor steel box girder", Advanced Materials Research, vol. 671-674, 2013, pp. 974-979.

[12] Giuliani M. E, Giuliani G. C. "Incremental launching of a wide span glazed roof", Structural Engineering International, vol. 17, July 2007, pp. 242-245. 